\title{
Structure and Mucopolysaccaride Type of Major Salivary Glands of the Sunda Porcupines (Hystrixjavanica)
}

\author{
Budipitojo T ${ }^{1 *}$, Ariana ${ }^{1}$ and FibriantoY ${ }^{2}$ \\ ${ }^{1}$ Department of Anatomy, Universitas Gadjah Mada, Indonesia \\ ${ }^{2}$ Department of Physiology, Universitas Gadjah Mada, Indonesia
}

*Corresponding author: Teguh Budipitojo, Department of Anatomy, of

\section{Research Article}

Volume 2 Issue 3

Received Date: June 20, 2017

Published Date: August 04, 2017

Veterinary Medicine, Universitas Gadjah Mada, Yogyakarta 55281, Indonesia, Tel: 081392130161; Email: budipitojo@ugm.ac.id

\section{Abstract}

Sunda porcupines are one of the rodent species endemic to Indonesia. There is lack information related to the anatomical structure of their major salivary glands. The study aims to identify the anatomical structures and types of mucopolysaccharides produced by the major salivary glands of Sunda porcupine. Four tissue samplesof major salivary glands of Sunda porcupine were processed for paraffin method and analyzed by Hematoxylin-Eosin, Alcian Blue-Periodic Acid Schiff, and lectin histochemistry for saphora japonica agglutinin and wheat germ agglutinin. The parotid gland found in the preauricular region and along the posterior surface of the mandible, while the submandibular and sublingual glands were located on the floor of the mouth posterior to each mandibular canine. The parotid gland was divided into two lobules, each composed by different types of acini in a separate lobulation. HE staining showed that parotid gland looks unique because in the anterior lobe, the acini are dominated by serous celltype, while in posterior lobe are composed by mixed of serous and mucous cell-types. The acini of submandibular gland consist of serous cells-type, but sublingual gland acini covered by mucous cell-type. All of three major salivary glands have complete duct system comprising intercalated, striated and excretory ducts. The acini of parotid, submandibular, and sublingual glands contain acid and neutral, neutral, and acid mucopolysaccharides, respectively. Lectin staining using SJA and WGA indicates that acini in salivary glands of sunda porcupine contain sugar residue of $\mathrm{N}$-acetylgalactosamine and $\mathrm{N}$-acetylglucosamine which is a derivative of galactose and glucose by the order of intensity from weak to strong in the parotid, sublingual and submandibular glands.The present results provide for the first time data on the anatomical structure and mucopolysaccharides type produced by major salivary glands of Sunda porcupines. Sunda porcupine, major salivary gland, anatomical structure, mucopolysaccharides.

Keywords: Structure morphology; Mucopolysaccaride type; Salivary glands; Sunda porcupines

\section{Introduction}

The Sunda porcupines (Hystrixjavanica) are one of the rodent species endemic to Indonesia. Although the conservation status of Sunda porcupine is the least concern, their populations in the wild tend to dramatically decrease due to high interest of human consumption. Moreover, there is lack information on the anatomical structure of their organ systems.

The Sunda porcupine has a distinct gastrointestinal system, especially for their extramural organs. For example, the histological structure of pancreatic tissues 
of Sunda porcupine almost similar to the other mammalian species [1] which contains four types of major pancreatic endocrine cells with approximately similar distribution patterns to the other rodents, except for abundant glucagon cells in the peripheral area of the islets of Langerhans [2].

Histochemistry can be defined as the chemistry of tissue components and its relation to tissue morphology. In histochemical study, lectins have extensively been used as probes in studying the cell surface interaction and carbohydrate composition in many tissues because lectins, naturally polypeptides, can bind specifically to carbohydrate residues in term of glycoconjugates [3]. Many authors have focused on the importance of glycoconjugates in salivary glands of mammalian species and correlated them with body functions such as, transporting of macromolecules for digestive efficiency, preventing proteolytic damage on epithelia, and defending against bacteria $[4,5]$.

Histological structures and types of mucopolysaccharides produced by the major salivary glands of Sunda porcupine, however, are not available. Therefore, the study was conducted conventional staining for histological analysis and lectin histochemical methods for detecting sugar residues in the glycoconjugates of major salivary gland.

\section{Materials and Methods}

porcupines, Hystrixjavanica, about $67 \mathrm{~cm}$ in length were purchased from a merchant in Tawangmangu, Central java, Indonesia were used as samples. Salivary gland tissues of Hystrixjavanica were fixed for 24 hours in Bouin's solution, dehydrated in ethanol, cleared in xylene, and embbeded in parrafin.

Tissue samples of major salivary glands (parotid, submandibular and sublingual glands) were processed for paraffin method, cut serially in $4 \sim 5 \mu \mathrm{m}$ thickness and stained by hematoxylin and eosin (HE) for conventional histological evaluation. Alcian BluePeriodic Acid Schiff (AB-PAS) and lectin histochemistry for saphora japonica agglutinin (SJA) and wheat germ agglutinin (WGA) were applied for further analysis of sugar residues in the glycoconjugates of major salivary gland. Sections were examined with a conventional light microscope, and photomicrographs were taken with OptiLab digital camera.

\section{Results and Discussion}

\section{Results}

The parotid gland was found in the posterior of masseter muscle and the upper parts of the sternocleidomastoid muscle, while the submandibular and sublingual glands were located in close proximity on the floor of the mouth posterior to each mandibular canine (Figures 1).

Four major salivary glands of adult Sunda

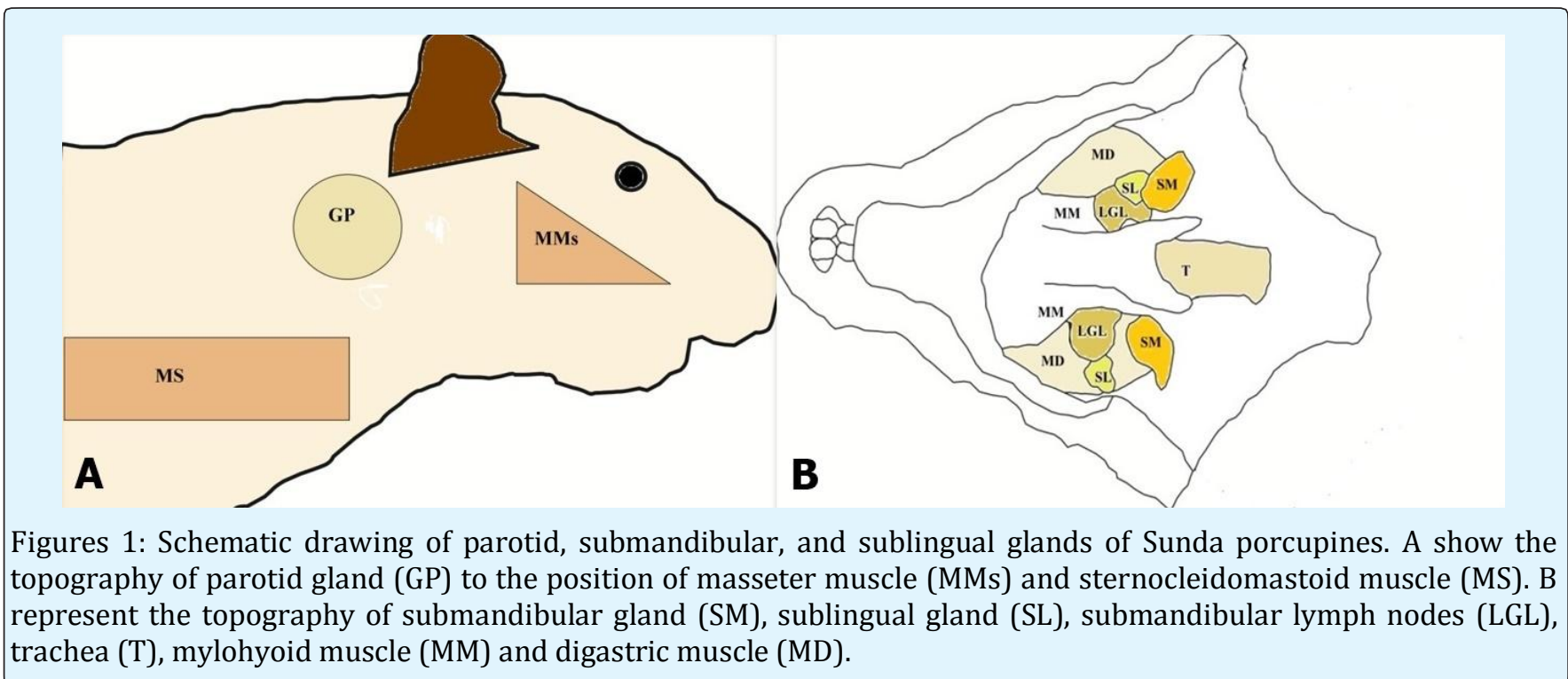

The parotid gland looks unique because it is divided into two lobes, and each lobe composed by different types of acini in separated lobes (Figure 2). The acini in the anterior lobe of parotid glands positive with PAS, indicated the serous cell-type composition, while the acini of posterior lobe of parotid gland are positive with $\mathrm{AB}$, indicated the domination of mucous cell-type (Figure 2). 


\section{Open Access Journal of Veterinary Science \& Research}

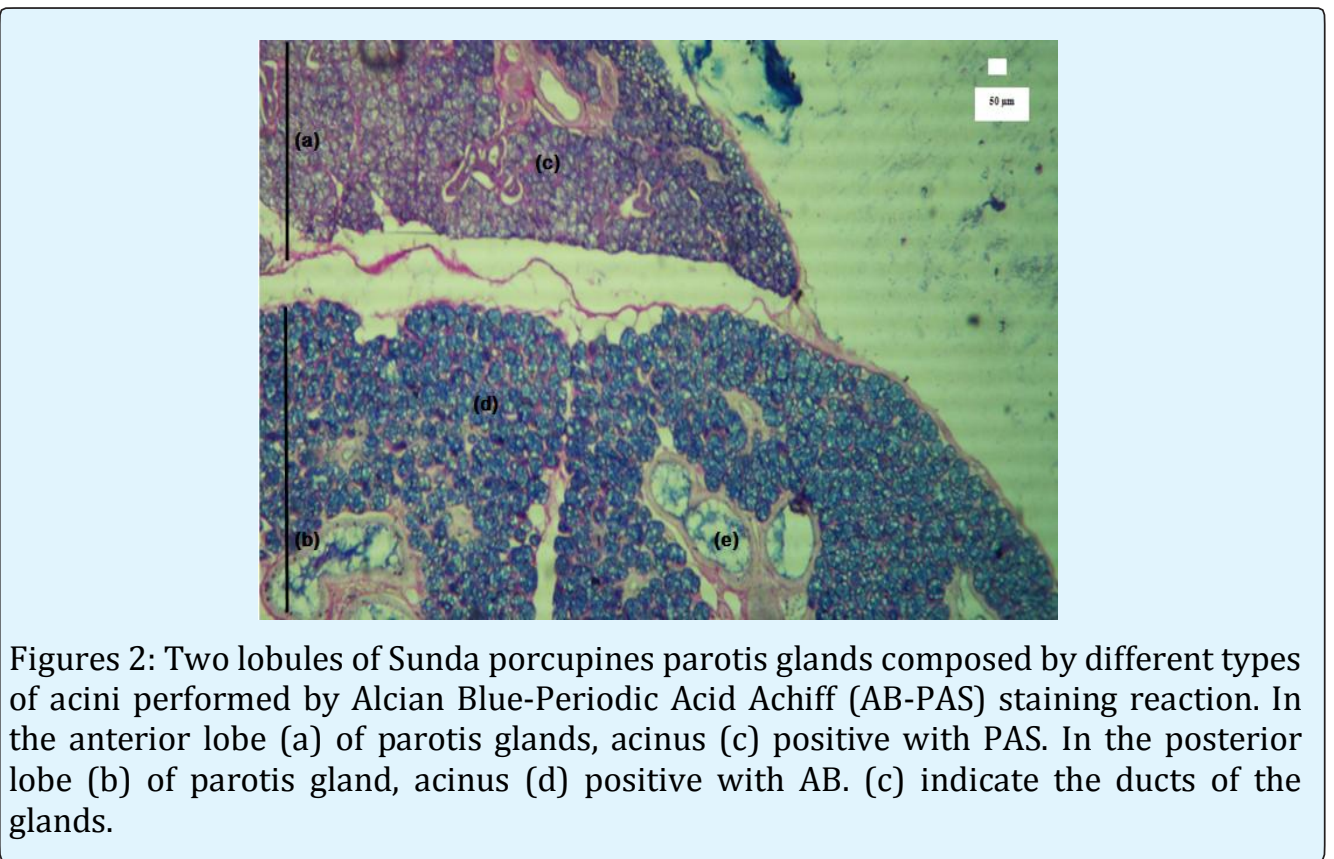

Histological examination with HE and AB-PAS stained sections revealed that the submandibular and sublingual glands were located in close proximity, separated by thin fibrous connective tissue. The AB-PAS staining showed that submandibular gland acini consist of serous cells-type and sublingual gland acini are covered by mucous cell-type (Figures 3). Higher magnification on the acinus of parotid gland revealed the domination of serous cell-type in anterior lobe and mucous cell-type in posterior lobe of the gland (Figure $3)$.

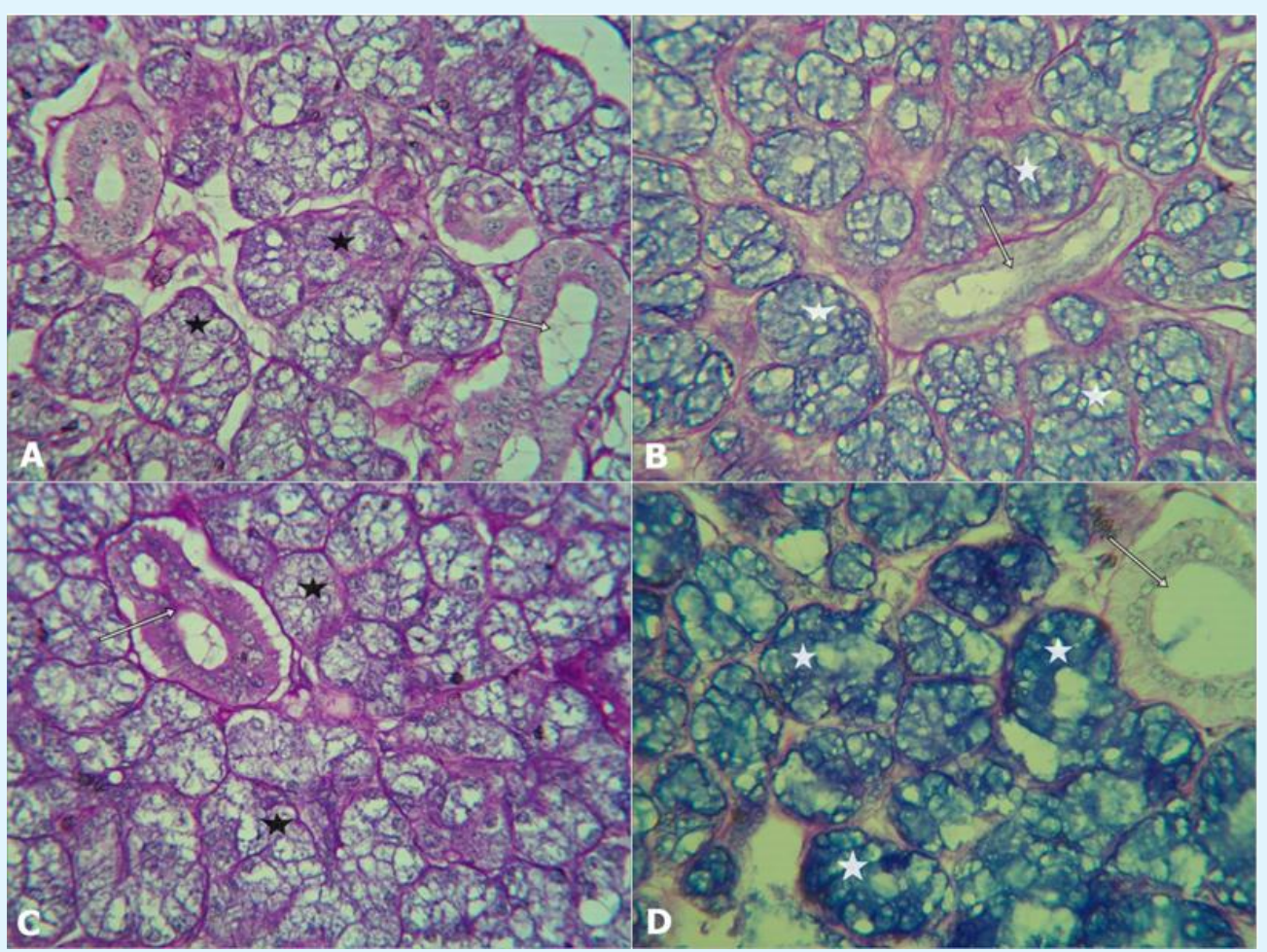

Figure 3: Alcian Blue-Periodic Acid Achiff (AB-PAS) staining reaction in the submandibular, sublingual and parotis glands of Sunda porcupines (520x). The submandibular (A) and anterior lobe of parotid glands (B) positive with PAS. The sublingual (C) and posterior lobe of parotid gland (D) positive with AB. Stars and arrows indicated the acini and ducts of the glands. 


\section{Open Access Journal of Veterinary Science \& Research}

The results of Lectin histochemistry staining section for SJA and WGA in the major salivary glands (submandibular, sublingual, and parotid glands)of Sunda porcupine revealed that SJA and WGA are detected with various intensities from weak to strong (Figure 4). Lectin histochemistry method showed that
SJA is detected strong in the submandibular gland, medium in sublingual gland and weak in parotid gland of Sunda porcupine. In agreement with SJA, WGA is also detected strong in the submandibular gland, medium in sublingual gland and weak in parotid gland of Sunda porcupine (Figure 4).
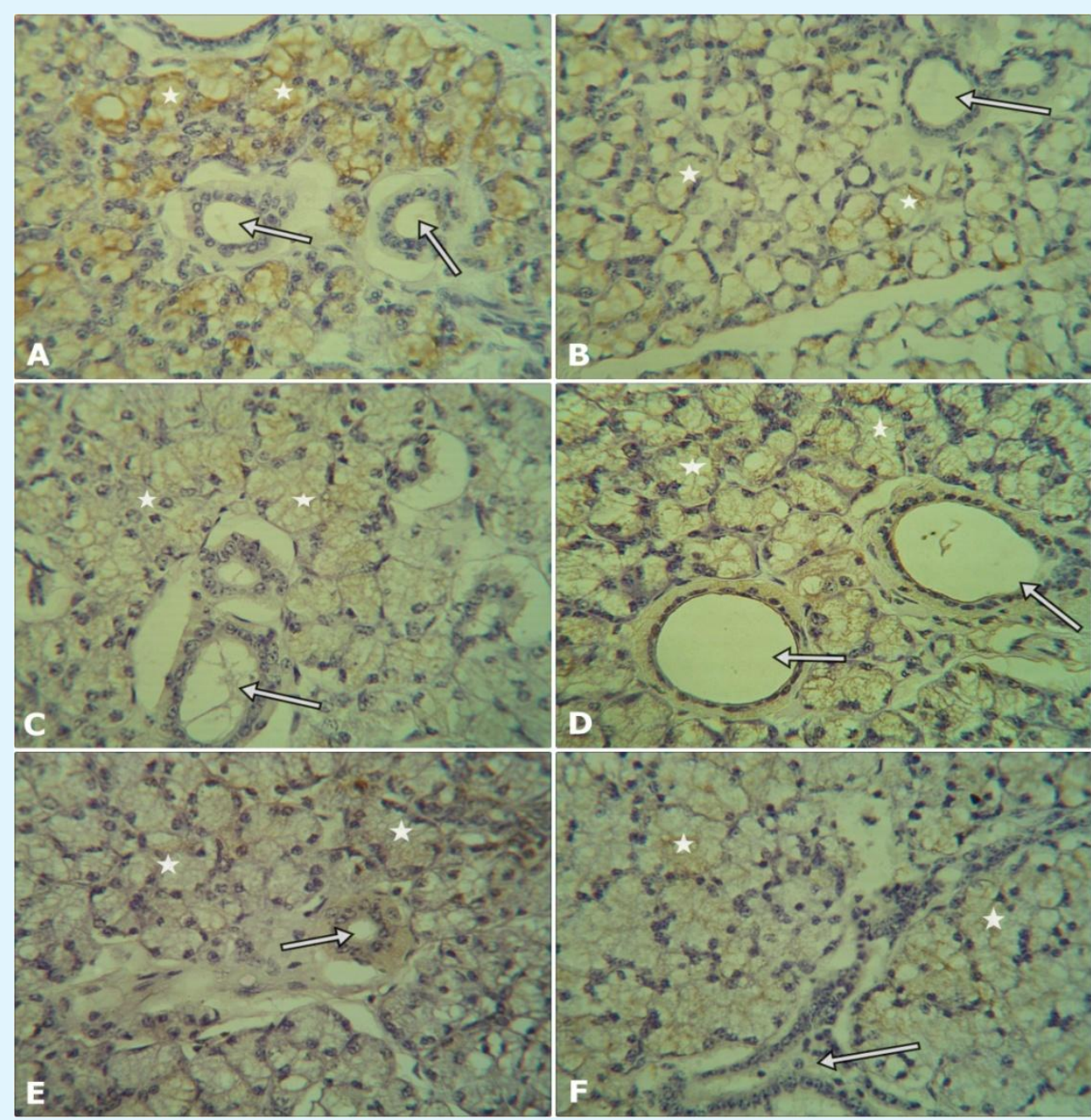

Figure 4: Lectin histochemistry for saphora japonica agglutinin (SJA) and wheat germ agglutinin (WGA) in the major salivary glands of Sunda porcupine (520x). Lectin histochemistry method showed that SJA (A, B, C) and WGA (D, E, F) were detected in all major salivary glands of Sunda porcupine by the order of intensity from strong, medium and weak in the submandibular, sublingual and parotidglands, respectively. Stars and arrows indicated the acini and ducts of the glands.

\section{Discussions}

Routine histological examination of HE and AB-PAS stained sections revealed that the submandibular and sublingual glands were located in close proximity, separated by thin fibrous connective tissue. As a major salivary gland of the body, submandibular, sublingual and parotid glands of different rodents shows a variety in the lobes and form of its secretory end pieces. In agreement with our finding in Sunda porcupine, the submandibular and sublingual secretory end pieces of rat [6] and european hamster [7] showed serous and seromucosa cell-types, respectively. However, in contrast with other rodents which consist of 1 lobe with serous cell-type acini $[6,7]$, the parotid gland of Sunda porcupine consist of 2 lobes with serous cell-type in the anterior lobe and mucous cell-type in the posterior lobe.

In the present study, the three major salivary glands of Sundaporcupin have complete duct system comprising intercalated, striated and excretory ducts. Similar results were found in the rodents $[6,7]$.

The acini of submandibular gland contain neutral mucopolysaccharides, sublingual glands contain acid mucopolysaccharides and the parotid gland contains 


\section{Open Access Journal of Veterinary Science \& Research}

acid and neutral mucopolysaccharides according to the AB-PAS staining method. The acidic mucopolysaccharides are thought to contain terminal sialic acid residues [8] and neutral mucopolysaccharides compose of free aldehyde groups within the monosaccharide units [9]. Predominant glycoconjugates with terminal sialic acid in serous cells may coat the mucosal surface so as to provide an environment designed to preserve hydration [10] and to protect the cell from pathogenic organisms $[11,12]$.

The identification of sugar residues was improved by using lectin histochemistry in comparison with conventional histochemistry. Lectin histochemistry method showed that SJA and WGA were detected in all major salivary glands of Sunda porcupine by the order of intensity from weak to strong in the parotid, sublingual and submandibular glands. Lectin staining using SJA indicates that acini in salivary glands of sunda porcupine contain sugar residue of $\mathrm{N}$ acetylgalactosamine [13]. Lectin staining using WGA indicates that acini in salivary glands of sunda porcupine contain sugar residue of $\mathrm{N}$-acetylglucosamine which is a derivative of glucose [14] and N-acetyl neuraminic acid residue $[15,16]$. The presence of this sugar residue may play defensive function in the region of the mouth of Sunda porcupine, since in the mucosa and mucous of gastric, neuraminic acid is important for entrapping a wide variety of microorganisms [17].

\section{Conclusion}

The present results provide the first time data on the histological structure and mucopolysaccharides type produced by major salivary glands of Sunda porcupines. In general, the histological structure of Sunda porcupine major salivary glands similar to the other rodents except for the parotid gland which consist of 2 lobes with serous cell-type in the anterior lobe and mucous cell-type in the posterior lobe. Lectin staining using SJA and WGA indicates that acini in salivary glands of sunda porcupine contain sugar residue of Nacetylgalactosamine and $\mathrm{N}$-acetylglucosamine which is a derivative of galactose and glucose by the order of intensity from weak to strong in the parotid, sublingual and submandibular glands.

\section{Acknowledgment}

This study was fully supported by the Grant for Scientific Research (PUPT UGM 2016) from the Directorate General of Higher Education (DIKTI), Ministry of Research, Technology and Higher Education of Indonesia with contract number 112/LPPM UGM/2016.

\section{References}

1. Budipitojo T, Fibrianto Y H, Mulyani GT, Kondoh D, Sasaki M, et al. (2016) The pancreas morphology of Sunda porcupine (HystrixJavanica). J Vet Adv 6(2): 1211-1216.

2. Budipitojo T, Fibrianto YH, Mulyani GT (2016) The types of endocrine cells in the pancreas of Sunda porcupine (Hystrixjavanica). Vet World 9(6): 563-567.

3. Alroy J, Ucci AA, Pereira MEA (1988) Lectin histochemistry. An update. In: advances in immunohistochemistry. Raven Press, New York, 93131.

4. Berger EG, Buddecke E, Kamerling JP, Kobata A, Paulson JC, et al. (1982) Structure, biosynthesis and function of glycoproteins glycans. Experientia 38: 11291262.

5. Danguy A, Akif F, Pajak B, Gabius HJ (1994) Contribution of carbohydrate histochemistry to glycobiology, HistolHistopathol 9: 155-171.

6. Amano O, Mizobe K, Bando Y, Sakiyama K (2012) Anatomy and histology of rodent and human major salivary glands. Acta Histo chem Cytochem 45(5): 241250.

7. Khojasteh SM, Delashoub M. (2012) Microscopic anatomy of the parotid and submandibular salivary glands in European hamster (Cricetuscricetus L.). IRJABS 3(7): 1544-1548.

8. Suprasert A, Fujioka T (1987) Lectin histochemistry of glycoconjugates in esophageal mucous gland of the chicken. Jpn J Vet Sci 49: 555-557.

9. Goldstein IJ, Hayes CE (1978) The lectins: carbohydrate binding proteins of plant and animal. Adv Carbohydr Chem Biochem 35: 127-340.

10. Jeanloz RW, Codington JF (1976) The biological role of sialic acid at the surface of the cell. In: Biological roles of sialic acid. Plenum Press. New York 201238.

11. Montreuil J (1980) Primary structure of glycoprotein - glycans: basis for the molecular biology of glycoproteins. Adv Carbohydr Chem Biochem 37: 157-213.

12. Schulte BA, Spicer SS, Miller RL (1984) Histochemical localization of sialoglycoconjugates with a sialic acid specific lectin from the slug Limaxflavus. J Histochem 16: 1125-1132. 


\section{Open Access Journal of Veterinary Science \& Research}

13. Al-Banaw A, Kenngott R, Al-Hassan JM, Mehana N, Sinowatz F (2010) Histochemical analysis of glycoconjugates in the skin of a catfish (ariustenuispinis, day). Anat Histol Embryol 39(1): 42-50.

14. Park C, Ahn M, Kim J, Kim S, Moon C, et al. (2015) Histological and lectin histochemical studies on the olfactory mucosae of the Korean roe deer, Capreoluspygargus. Tissue Cell 47(2): 221-227.

15. Ishida K, Suganuma T, Tsuyama S, Murata F (1988) Glycoconjugatehistochemistry of the rat fundic gland using Griffoniasimplicifolia agglutinin-II during the development. Am J Anat 182(3): 250-256.

16. Bogoeva V, Radeva M, Atanasova L, Stoitsova S, Boteva R (2004) Fluorescence analysis of hormone binding activities of wheat germ agglutinin. Biochem Biophys Acta 1698(2): 213-218.

17. Madrid J, Ballesta J, Castells M, Marin J, Pastor L (1989) Characterization of the glycoconjugates in the intestinal mucosa of vertebrates by means of lectin histochemistry. Acta Histochem Cytochem 22: 1-12. 